\title{
GESTÃO DOS INSTITUTOS FEDERAIS: O DESAFIO DO CENTENÁRIO DA REDE FEDERAL DE EDUCAÇÃO PROFISSIONAL E TECNOLÓGICA
}

\author{
Francisco das Chagas de Mariz Fernandes \\ Professor do Instituto Federal-RN, Graduado em Engenheiro Civil, Especialista em Gestão \\ da Educação Tecnológica e Mestre em Engenharia de Produção. \\ E-mail: mariz@cefetrn.br
}

\section{RESUMO}

Os Institutos Federais de Educação, Ciência e Tecnologia surgiram no contexto de expansão e valorização da educação profissional desencadeado pelo Governo Lula no país, a partir do ano de 2003, através de um plano estruturante de expansão da Rede Federal de Educação Profissional e Tecnológica, que, até 2010, terá passado de 140 para 354 instituições. Nesse contexto, a proposta de constituição de 38 Institutos Federais para integrar a maior parte dessas unidades de ensino, a partir do exercício de 2009, quando a Rede chega ao seu centenário, representa imenso desafio, considerando os processos de mudança de gestão a que terão de se submeter para se adequar à nova realidade institucional. Cada Instituto Federal é estruturado com uma Reitoria e vários Campi, com gestão interdependente entre ambos. Territorialmente, à Reitoria competirá a função estratégica de definição de políticas, supervisão e controle. Para tanto, necessita de uma estrutura administrativa que congregue, além do gabinete, pró-reitorias e diretorias de atuação sistêmica, cabendo a esses órgãos a função de trabalhar matricialmente vinculados às unidades afins dos Campi. Cada Campus, por sua vez, responsável pela execução dos objetivos finalísticos institucionais, necessita de uma estruturação híbrida, através da associação da departamentalização funcional e a matricial - para viabilizar o diálogo e interação dos departamentos da área acadêmica com as unidades operacionais dos demais departamentos das áreas de administração, de apoio ao ensino, de extensão e de pesquisa. Na realidade, o arranjo situacional dos Institutos Federais é novo e caracteriza-se como próprio de uma estrutura em rede, para integrar sistemicamente diversas organizações de ensino através de um núcleo central - no âmbito nacional, através da Secretaria de Educação Profissional e Tecnológica do Ministério da Educação, e no espaço regional, os vários Campi, através de uma Reitoria.

PALAVRAS-CHAVE: Gestão; Educação Profissional; Expansão; Rede Federal; Instituto Federal. 


\begin{abstract}
The Federal Institutions of Education, Science and Technology had emerged in the context of expansion and valuation of the professional education unchained in the country by Lula's Government, since the year 2003, through a structuring plan of expansion of Federal System of Professional and Technological Education, that, up to 2010, will have passed from 140 to 354 institutions. In this context, the proposal of establishing 38 Federal Institutions to integrate the biggest part of these education units, from the year 2009, when the system gets centenarian, represents an immense challenge, considering the change of the management processes that it will have to be subjected to adjust itself towards the new institutional reality. Each Federal Institution is structured with a Rectory and some campuses, with interdependent management between both. Territorially, to the Rectory will comprehend the strategic function of politics definition, supervision and control. To achieve it, needs an administrative structure that congregates, beyond the cabinet, prorectories and systemic performance directorates, being responsibility of these agencies the function of working matrically entailed to the similar units of the campuses. Each Campus, therefore, responsible for the execution of finalistic institutional objectives, needs a hybrid structuring, through the association of functional and matrix departmentalization - to make possible the dialogue and interaction of the academic area departments with the operational units of the others departments of administration areas, education support, extension and research. In reality, the situational arrangement of the Federal Institutions is new and characterized as proper of a network structure, to systematically integrate several organizations of teaching through a central nucleus - in national scope, through the Professional and Technological Education Secretariat of the Ministry of Education, and in regional scope, some Campuses through a Rectory.
\end{abstract}

KEYWORDS: Management; Professional Education; Expansion; Federal System; Federal Institution. 


\section{INTRODUÇÃO}

Com a criação das 19 Escolas de Aprendizes Artífices nos diversos Estados da Federação, em 23 de setembro de 1909, o Presidente Nilo Peçanha, através do Decreto $n^{\circ}$. 7.566, lança a pedra fundamental da rede federal de educação profissional no país. Vivenciando os avanços e dificuldades da sociedade brasileira do século XX, em 1959, portanto 50 anos após o seu surgimento, a rede é premiada com a transformação das instituições que naquele momento a representavam, em Escolas Técnicas Federais - autarquias com autonomia didática, administrativa e financeira, que se firmaram como referência na qualidade do ensino. Passado mais meio século, no ano do seu centenário, a rede é instituída oficialmente pela Lei $\mathrm{n}^{\circ}$. 11.892, de 29 de dezembro de 2008, publicada no Diário Oficial da União de 30 de dezembro de 2008, no âmbito do sistema federal de ensino, como Rede Federal de Educação Profissional, Científica e Tecnológica, vinculada ao Ministério da Educação e constituída por 38 Institutos Federais de Educação, Ciência e Tecnologia Institutos Federais, pela Universidade Tecnológica Federal do Paraná, pelos Centros Federais de Educação Tecnológica Celso Suckow da Fonseca e de Minas Gerais e por 24 Escolas Técnicas Vinculadas a Universidades Federais.

Neste momento em que surge uma nova configuração para os estabelecimentos educacionais da rede - os Institutos Federais, criados mediante a transformação e/ou integração de 31 Centros Federais de Educação Tecnológica, 39 Escolas Agrotécnicas Federais, sete Escolas Técnicas Federais e oito Escolas Técnicas Vinculadas a Universidades Federais -, vislumbra-se um cenário de profundas mudanças na gestão e atuação das instituições que a compõem. Estas precisarão se reorganizar como estruturas multicampi, visando atender a função social alvo de suas finalidades e objetivos, através de uma ação acadêmica que garanta, em cada exercício, o mínimo de $50 \%$ das vagas para cursos técnicos de nível médio, bem como, no mínimo, $20 \%$ das vagas da educação de nível superior para cursos de licenciaturas e/ou programas especiais de formação pedagógica, visando à formação de professores para a educação básica e para a educação profissional.

Dessa forma, o contexto dispõe a estruturação e o funcionamento dos Institutos Federais como o desafio do ano do centenário para toda a rede. Partindo da realidade ora vivenciada, existe um largo caminho a percorrer com vistas ao atendimento dos pressupostos delineados pelo governo federal para os Institutos Federais de Educação, Ciência e Tecnologia, especialmente quanto ao fato de se constituírem com uma identidade única e estrutura multicampi, o que requer uma organização administrativa inovadora, com bases próprias de rede.

\section{AS INSTITUIÇÕES FEDERAIS DE EDUCAÇÃO PROFISSIONAL E TECNOLÓGICA}

O modelo atual de estrutura organizacional das instituições federais de educação profissional e tecnológica, salvo algumas exceções, caracteriza-se como do tipo funcional e verticalizado, compreendendo um padrão de departamentalização em vários níveis, o que sugere a possibilidade de uma rígida hierarquização. Apesar de algumas dessas instituições já possuírem mais de uma unidade de ensino, não se vislumbra, nos respectivos organogramas, uma forma de articulação sistêmica entre tais unidades. No momento em 
que há uma reorganização da rede, através da criação dos Institutos Federais, torna-se importante compreender que as atuais estruturas departamentalizadas das instituições que a compõem não são adequadas à nova proposta de gestão.

\begin{abstract}
"A departamentalização é uma forma de utilizar a cadeia de comando a fim de agrupar pessoas para que executem juntas o seu trabalho. Existem cinco abordagens de desenho departamental. As abordagens tradicionais são a departamentalização funcional, a divisional e a matricial, nas quais a cadeia de comando define agrupamentos departamentais e relações de subordinação ao longo da hierarquia. As duas abordagens contemporâneas são o uso de equipes $e$ de redes e surgiram para atender às necessidades das organizações em um ambiente global altamente competitivo." (CHIAVENATO, 1999, p. 396).
\end{abstract}

Sob essa perspectiva, a concepção de organização que surge, vai precisar ser muito dinâmica, própria de uma estrutura em rede, para integrar sistemicamente, através de uma reitoria, os diversos campi situados numa determinada extensão territorial. Trata-se de uma abordagem inovadora que pretende viabilizar o funcionamento e o controle da organização em toda uma região, garantindo a oferta de uma educação pública eficaz e de qualidade.

Na prática, a proposta dos Institutos Federais compreende uma estruturação própria de uma organização composta de várias organizações, situação própria das grandes instituições, que se apóiam em estruturas híbridas, sendo inviável, portanto, na sua gestão, a aplicação de um único tipo de forma organizacional. Nessa realidade de enfoque sistêmico, o Instituto Federal passa a ser um conjunto de Unidades com gestão interdependente entre os campi e a reitoria, integrados por princípios institucionais estratégicos, inclusive projeto político-pedagógico único, com foco na justiça social e equidade.

\title{
O DESIGN ORGANIZACIONAL DOS INSTITUTOS FEDERAIS
}

A Lei $n^{\circ} .11 .892$, de 29 de dezembro de 2008, determina no caput dos seus artigos $9^{\circ}$ e 11 , respectivamente, que "cada Instituto Federal é organizado em estrutura multicampi, com proposta orçamentária anual identificada para cada campus e a reitoria, exceto no que diz respeito a pessoal, encargos sociais e benefícios aos servidores" e que "os Institutos Federais terão como órgão executivo a reitoria, composta por 1 (um) reitor e 5 (cinco) próreitores".

O modelo diferenciado e único dos Institutos Federais com relação às outras instituições educacionais do país, em virtude da atuação nos diversos níveis da educação nacional e da articulação do ensino com a pesquisa e extensão, além da organização estrutural multicampi e pluricurricular, conduz a uma nova institucionalidade e, consequentemente, exige novos procedimentos de gestão. Considerando que o novo é construído a partir do aperfeiçoamento da cultura existente, cabe, para a organização da reitoria, buscar a essência das funções institucionais estratégicas e táticas. De acordo com Morin (2000, p. 82):

\footnotetext{
"Toda evolução é fruto do desvio bem-sucedido cujo desenvolvimento transforma o sistema onde nasceu: desorganiza o sistema, reorganizando-o. As grandes transformações são morfogêneses, criadoras de formas novas que podem constituir verdadeiras metamorfoses. De qualquer maneira, não há evolução que não seja desorganizadora/reorganizadora em seu processo de transformação ou de metamorfose."
} 
Nesse sentido, à reitoria competirão as funções de definição de políticas, supervisão e controle. Para tanto, é necessário uma estruturação que congregue um gabinete e órgãos de assessoramento para assistência imediata ao reitor, além de unidades administrativas que deverão trabalhar matricialmente vinculadas aos órgãos afins dos campi. Dessa forma a estrutura compreende as cinco pró-reitorias previstas na legislação, cujas atuações são requeridas para as principais áreas de estrutura e funcionamento da instituição, a saber: acadêmica (denominação própria em função da especificidade da oferta verticalizada de ensino, que vai da educação continuada à pós-graduação, associada à pesquisa e extensão em todo o trajeto da formação acadêmica); de pesquisa e inovação; de extensão e integração instituto-sociedade; de desenvolvimento institucional; e de planejamento e administração. Conta ainda com cinco diretorias de atuação sistêmica, conforme segue: apoio às atividades estudantis (ação assumida como instrumento de inclusão, acompanhamento e manutenção dos estudantes na escola); engenharia e infraestrutura; educação à distância; gestão da tecnologia da informação; e gestão de pessoas - unidades necessárias ao atingimento do escopo funcional do Instituto. Para melhor visualização, segue abaixo uma representação do modelo descrito.

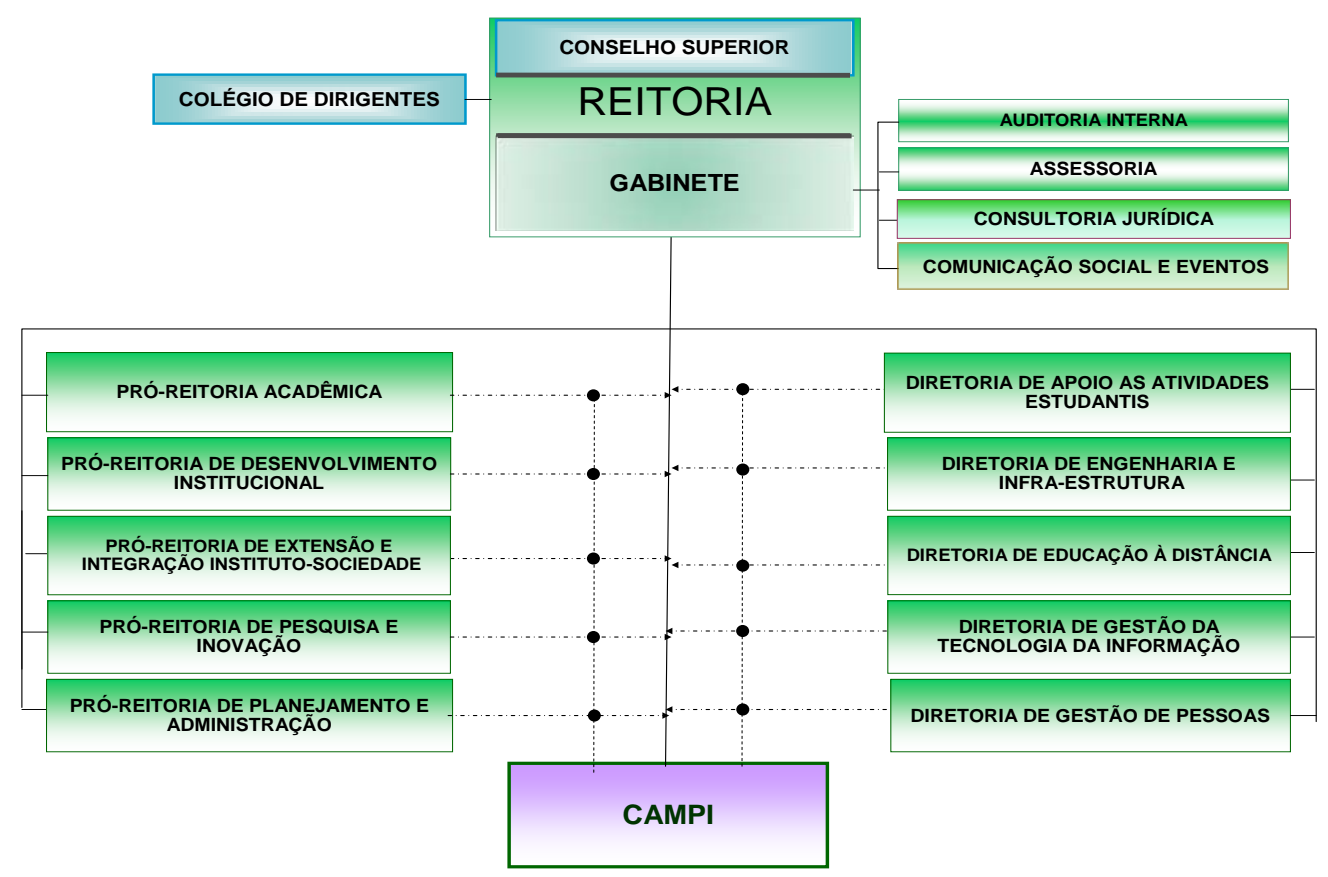

\section{Figura 1 - Modelo referencial de estrutura administrativa para Reitoria dos Institutos Federais}

Os campi, enquanto unidades de execução da ação educacional, responsáveis pelo cumprimento dos objetivos finalísticos do Instituto Federal, necessitam de uma estrutura administrativa híbrida, através da associação da departamentalização funcional e da matricial - que viabiliza o diálogo e a interação dos departamentos da área acadêmica com as unidades operacionais dos departamentos das áreas de administração, orçamento e finanças, de apoio ao ensino, de extensão e integração instituto-sociedade, de pesquisa e inovação e de gestão de unidade produtiva (quando houver). As diferentes dimensões e especificidades dos campi espalhados por todo o país implicam variados tamanhos de estruturas administrativas, em função dos quantitativos de cargos de direção e de funções gratificadas disponíveis para cada Instituto Federal. 
Respeitadas as diversidades e titulações de qualificação para as unidades administrativas, a representação circular, conforme a seguir apresentada, é adequada para os organogramas dos campi. Neste modelo de caráter generalista, a nomenclatura utilizada segue princípios de áreas funcionais básicas, com flexibilidade para incorporação de unidades organizacionais específicas.

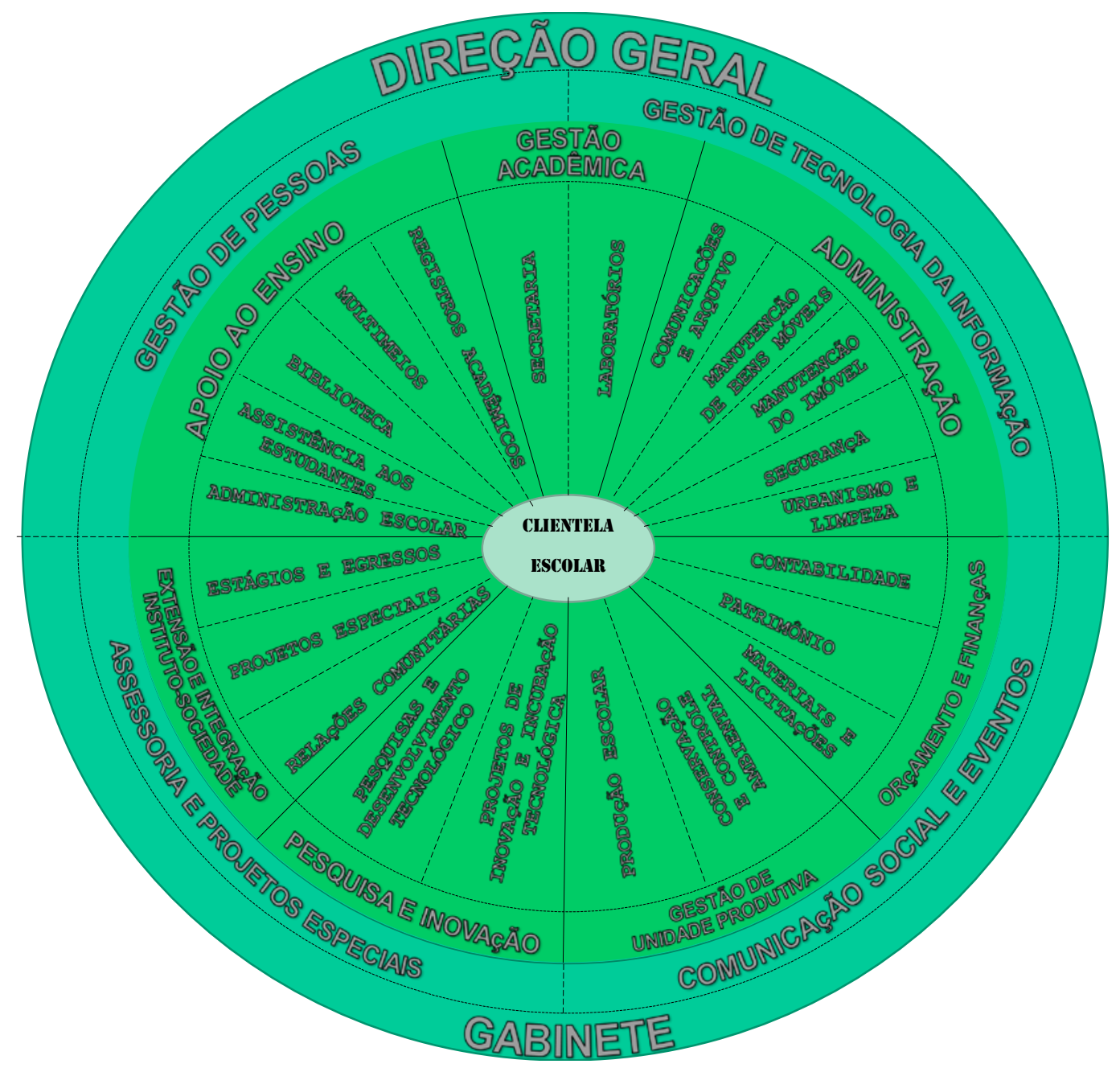

Figura 2 - Modelo referencial de estrutura administrativa para Campus dos Institutos Federais

\section{CONSIDERAÇÕES FINAIS}

Ao comemorar em 2009 os cem anos de criação das Escolas de Aprendizes Artífices, a comunidade que integra a Rede Federal de Educação Profissional, Científica e Tecnológica, passa por novo momento de reestruturação, com o desafio de organizar a gestão dos Institutos Federais, ou seja, ao se tornar centenária, começa um novo ciclo, uma nova história de superação, para viabilizar os Institutos Federais como as instituições de referência nacional na educação profissional e tecnológica do século XXI.

Em termos de gestão dos Institutos, não cabe olhar pelo retrovisor; o momento é para novas abordagens. A opção por uma estrutura híbrida, associando redes, para integrar sistemicamente os diversos campi através de um núcleo central - no caso a reitoria -, com 
um arranjo matricial e de departamentalização funcional em cada campus, deve ser perseguida com o objetivo de garantir a eficácia organizacional dessas instituições. Nesse novo contexto, será ferramenta decisiva o processo de planejamento institucional, viabilizando uma comunicação mais eficiente entre os diversos níveis da estrutura administrativa e oportunizando tomada de decisões mais rápidas e em consonância com as prioridades e a função social do Instituto Federal.

\section{REFERÊNCIAS BIBLIOGRÁFICAS}

1. BRASIL. Lei $\mathrm{n}^{\circ}$. 11.892, de 29 de dezembro de 2008. Institui a Rede Federal de Educação Profissional, Científica e Tecnológica, cria os Institutos Federais de Educação, Ciência e Tecnologia, e dá outras providências. Diário Oficial da União, Seção 1, p. 1, 30/12/2008.

2. BRASIL. Ministério da Educação. Educação Profissional e Tecnológica. Disponível na Internet. http://portal.mec.gov.br/setec. Acesso em 02/05/2008.

3. BRASIL. Ministério da Educação. Instituto Federal - Concepção e Diretrizes. Brasília, 2008.

4. CHIAVENATO, Idalberto. Administração nos novos tempos. Rio de Janeiro : Campus, 1999.

5. FERNANDES, Francisco das Chagas de Mariz. Estrutura e funcionamento dos Centros Federais de Educação Tecnológica. Trabalho apresentado na XXX REDITEC, Fortaleza-CE, 2006, mimeo.

6. MORIN, Edgar. Os sete saberes necessários à educação do futuro. São Paulo: Cortez, 2000.

7. PEREIRA, Luiz Augusto Caldas. Institutos Federais de Educação Ciência e Tecnologia. Disponível na internet. http://portal.mec.gov.br/setec/arquivos/pdf3/artigos ifet_jornal.pdf. Acesso em 02/05/2008.

8. TACHIZAWA, Takeshy e ANDRADE, Rui Otávio Bernardes de. Gestão de instituições de ensino. Rio de Janeiro : Fundação Getúlio Vargas, 1999. 